\title{
Article \\ Writing for Emotional Impact in Film and Video Games: Lessons in Character Development, Realism, and Interactivity from the Alien Media Franchise
}

\author{
Christian Thomas
}

Citation: Thomas, Christian. 2021. Writing for Emotional Impact in Film and Video Games: Lessons in Character Development, Realism, and Interactivity from the Alien Media Franchise. Arts 10: 20. https:// cdoi.org/10.3390/arts10020020

Academic Editor: Russell J A. Kilbourn

Received: 28 August 2020

Accepted: 18 March 2021

Published: 24 March 2021

Publisher's Note: MDPI stays neutral with regard to jurisdictional claims in published maps and institutional affiliations.

Copyright: (C) 2021 by the author. Licensee MDPI, Basel, Switzerland. This article is an open access article distributed under the terms and conditions of the Creative Commons Attribution (CC BY) license (https:// creativecommons.org/licenses/by/ $4.0 /)$.
Writing Program, University of California, Santa Barbara, CA 93106, USA; cthomas@writing.ucsb.edu

\begin{abstract}
This article compares Ridley Scott's film Alien (1979) with Creative Assembly's video game Alien: Isolation (2014), which is based on Scott's film. Guidance for academics who teach creative writing - as well as for working screenwriters and video game narrative designers-emerges in the comparison, particularly with regard to the importance of developing strong yet vulnerable main characters who put themselves in danger in order to protect other characters with whom they have meaningful relationships. Examples from other media, including Ira Levin's Rosemary's Baby (1967), James Cameron's Aliens (1986), Telltale Games' The Walking Dead (2012), and Naughty Dog's The Last of Us (2013), are also discussed as they relate to larger principles involved in crafting sympathetic characters, realistic settings, and compelling gameplay for media within the horror and sci-fi genres.
\end{abstract}

Keywords: creative writing studies; screenwriting; video game narrative design; interactive writing; horror film; horror video games; survival horror; character development; sci-fi; thriller

When game development company Creative Assembly (2014) released the video game Alien: Isolation, creative lead Alistair Hope's goal was to take inspiration from Scott (1979) film Alien, and to "re-establish it [the Alien] as the ultimate killer ... to re-Alien the Alien, to restore it to be something that seemed really incredible and extremely terrifying" (Price 2014). In order to achieve this goal of creating a newly energized Alien that would terrify players, Creative Assembly decided to focus their main efforts on creating a "oneon-one struggle", a game of "cat-and-mouse, hide and seek" where, as the title suggests, players are isolated from other characters (aside from the Alien, that is) for much of the game. While this approach has undoubted strengths-especially in terms of the tension and fear it can induce in players - the singular focus on a lonely struggle results in a game that is sparsely populated with characters who rarely have meaningful interactions. By contrast, the film Alien features an ensemble of richly developed characters who have complex relationships with each other. The main character in Alien, Ellen Ripley, is a strong yet emotionally vulnerable heroine who strives to protect others within a storyworld that feels realistic, even mundane in many ways - a backdrop which entices the audience to buy into the movie's more fantastic elements. Other films and video games that are related to Alien and Alien: Isolation—such as James Cameron's Aliens (1986), Telltale Games' The Walking Dead (2012), and Naughty Dog's The Last of Us (2013)—take a strikingly similar approach to the character development and worldbuilding employed in Alien. This highly successful approach can be considered for potential use by screenwriters and video game narrative designers working in horror and related genres, and for study by academics who research and teach creative writing, film, and video games.

In the beginning of the video game Alien: Isolation, we, as players, are introduced to the player-character we will inhabit-a woman named Amanda Ripley, who is the daughter of the film Alien's protagonist, Ellen Ripley-in a brief, two-minute cutscene. In this passive, cinematic scene, we watch Amanda as she receives an offer from an android named Samuels to accompany him to the space station Sevastopol, where the flight recorder 
of the Nostromo (Ellen Ripley's ship in Alien) is being kept. This cutscene does a lot of heavy lifting, character-wise, in a short span of time. In it, Samuels interrupts Amanda while she is welding, an act which communicates important information about her character: she is a tough, blue collar worker who knows how to handle a welding torch and probably other tools which we will later encounter in the game. (James Cameron takes a similar approach in the beginning of Aliens by having Ellen Ripley use a power loader; this helps to express her tough, capable character and sets up Ripley's use of the power loader when she later battles the Alien Queen Mother.) When the android introduces himself, saying, "I'm Samuels; I work for the Company", Amanda turns away from him and goes immediately back to welding. This gesture gives us a strong sense of her disdain for the Weyland-Yutani Corporation, which we know from the Alien films to be utterly ruthless and inhuman. But Samuels gets Amanda's attention again, and ours, by adding, "It's about your mother. We think we may have found her, Amanda." These words dangle the idea that we may actually be able to meet Ellen Ripley, in some way, in the game-although if players reflect on the notion, many may remember that in Cameron (1991) Aliens: Special Edition, which the game would be unlikely to contradict, Ellen Ripley is found floating in her shuttle two years after the death of her daughter Amanda, making it impossible for them to meet. It is not surprising, then, that soon after Samuels says the shocking words, "We think we may have found her", he explains the fine print: that it is not Ellen Ripley herself, but only the flight recorder of her ship, the Nostromo, that has been found and is being kept on Sevastopol Station. Samuels goes on to say that he knows Amanda has been in the region because she is still searching for her mother, and that if she comes to the space station with him, she might be able to find "closure".

Although closure may not be the most ambitious goal the writers (Dan Abnett, Dion Lay, and Will Porter) could have come up with, it has some emotional resonance, partly because players will likely be fans of the original film and of its heroine, Ellen Ripley. Samuel's words, "It's about your mother", also reflect an important motif that pervades the Alien films. As Keogh and Jayemanne $(2018$, p. 9) note, Alien: Isolation "engages with a mother/daughter complex central to the films but typically ignored by videogame adaptations", which begins to add an important dimension to the game, and helps it to rise above emotionally flatter predecessors, such as Aliens: Colonial Marines (Gearbox Software 2013).

The manifestations of the mother/daughter complex in Alien media are often horrific, such as the existence of the Queen Mother in Aliens, or the way the Xenomorph gestates inside its victims in a terrifying perversion of motherhood. The Alien films' most important engagement with the mother/daughter complex, however, likely belongs in the realm of character development. Figures like Ellen Ripley and Newt in Cameron's Aliens, for example, have a strong mother-daughter bond which creates intense emotional stakes that are at the core of the film's success: according to Weise and Jenkins (2009), Aliens sets a "high standard for affective intensity" not because the monsters look scary and the action scenes are explosive, but specifically because Cameron creates "a complex set of interrelationships between his characters, firmly establishing the emotional stakes in every sequence, and thus combing character actions and reactions in such a way that we never lose track of what the events mean for the people involved" (Weise and Jenkins 2009, p. 112). In short, the emotional stakes created by relationships between characters like Ellen Ripley and Newt are the biggest driver of affective intensity in Aliens.

The writers of Alien: Isolation wisely take a similar approach in the beginning cutscene of the game, tapping into the relationship between the player-character Amanda Ripley and her mother Ellen. In addition to offering players an emotional goal (powered by the mother-daughter bond) the cutscene also helps us, as players, to attach to Amanda Ripley by allowing us to see a vulnerable moment in which she expresses her grief. This comes in the form of Amanda's reaction to Samuels's words, "I know why you're working in the region where she went missing. You're still looking, aren't you? I've been cleared to offer you a place on the Torrens if you want to come along [to Sevastopol Station]. Maybe there'll be some closure for you". As Samuels speaks, Amanda responds only with 
her expression, and our hearts go out to her ${ }^{1}$-literally, in fact, since as we take in her grief-stricken expression (see Figure 1), the sound of a beating heart slowly rises in the background, getting faster. This subtle audio cue heightens our sense of vicarious grief and also of excitement as the adventure begins.

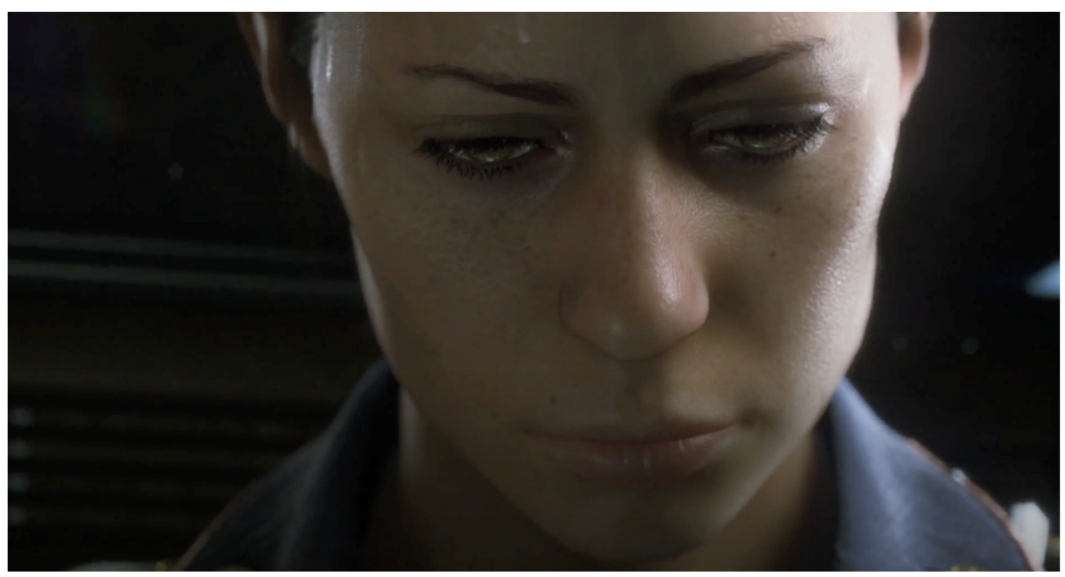

Figure 1. Amanda Ripley's face expresses empathy-inducing grief as Samuels says, “Maybe there'll be some closure for you."

The two-minute cutscene moves the story along at breakneck speed, comprising the entire first act, at least as measured by the stages of the monomyth, or Hero's Journey-a story form identified by Campbell (1949) in his work, The Hero with a Thousand Faces, and famously used by George Lucas while writing the third draft of the screenplay for the 1977 film Star Wars (Rinzler 2007, pp. 46-47). ${ }^{2}$ According to Christopher Vogler-who, as a story analyst for Disney in the mid-1980s, popularized the Hero's Journey among Hollywood executives and screenwriters (Iacobo 1994) - the first act of the Hero's Journey in a film should be robust, consisting of four distinct stages: The Ordinary World, The Call to Adventure, Refusal of the Call, and Meeting with the Mentor (Vogler and McKenna 2011).

The two-minute opening cutscene in Alien: Isolation quickly completes the first stage of the Hero's Journey by giving us a glimpse of the grief-filled, ordinary world of welder Amanda Ripley - a world which, according to Vogler, should stand in contrast to the place where the hero will end up at the end of the story (p. 35). In this case, we may assume that the storytellers have in mind an end point involving the peace of mind that comes from closure, perhaps within the context of a newly forged mother-daughter bond.

The second stage, The Call to Adventure, is represented by Samuel's invitation to go after the flight recorder from her mother's escape shuttle, while the third stage, Refusal of the Call, is completely skipped, as Amanda immediately accepts Samuels' offer. There is an opportunity missed here, since the Refusal of the Call is a place where the heroine can show the internal struggle involved with facing an intensely emotional problem. The fourth stage, Meeting with the Mentor, which represents the final stage of the first act in Vogler's scheme, is also skipped in Alien: Isolation. It may seem at first glance that Meeting with the Mentor should only apply to certain types of stories, such as George Lucas' 1977 film Star Wars, which successfully features a mentor figure in the character of Obi-Wan

1 In "The Walking Dead, Mirror Neurons, and Empathy", Madigan (2012) highlights the importance of featuring facial expressions in horror video games (specifically Telltale Games' The Walking Dead) by drawing on Marco Iacoboni's research into mirror neurons. Madigan writes, "When we see Lee Everett or any of the other Walking Dead characters grimace in disgust, our mirror neurons for grimacing activate as if we were making that expression ourselves. And because of that inner imitation, we actually do feel the emotion to some degree and understand what the other is feeling".

2 The Hero's Journey has been applied not only to film, but to video games by numerous scholars (see, for example, Delmas et al. 2007; Ip 2011; Lebowitz and Klug 2011; Pugh 2018) and game designers (see Dunniway 2000; Bates 2005; Costuic 2016). Alien: Isolation lends itself particularly well to analysis through the lens of the Hero's Journey and other cinematic narrative techniques because the game's roots in film and the components (including a substantial and important narrative) that it shares with Alien and Aliens. 
Kenobi. But as Vogler describes, the Meeting with the Mentor need not involve a mentor in the literal sense: in this stage, the hero can also reach "within to a source of courage and wisdom" (Vogler and McKenna 2011, p. 33). Getting to see Amanda struggle with facing the possibility of discovering that her mother is truly dead-dashing her greatest hopes-might help us, as players, to feel a greater sense of the emotional stakes involved, to bond with Amanda and buy into the story at a deeper level.

One reason for the exclusion of Refusal of the Call and Meeting with the Mentor may be that the writers of Alien: Isolation felt pressured to minimize the time spent in cutscenes, since players can be impatient with passively watching cutscenes instead of getting to actively play the game. Part of the problem here is that cutscenes are too often the default place for "story" in games, possibly because game writers habitually draw on the way characters are developed in film.

But while cutscenes can undoubtedly be effective in delivering story, character and plot development can (and should, in many cases) occur outside of these passive cinematic moments, too. In The Walking Dead (Telltale Games 2012), for example, which won the BAFTA Games Award for Story in 2013, the player makes choices that determine what the player-character says and does; in doing so, the player develops their character through the act of playing, as opposed to passively watching character development occur in cutscenes. $^{3}$

The writers of The Walking Dead do employ passivity, though, but by offering "passive choices", in an interesting contradiction of usual notions of player agency. In fact, some of the most poignant moments in The Walking Dead are a consequence of the playercharacter choosing to say nothing (dialog choices in The Walking Dead usually include a silent or passive choice, indicated by an ellipsis), but this is extremely perilous for players, since saying nothing usually brings negative consequences. Other powerful moments in The Walking Dead feature choices where the player can save only one of two non-player characters (NPCs) who are in danger: the power of these moments lies in the fact that the choices are tied to serious consequences for relationships involving characters that the player has come to care deeply about.

It may seem counter-intuitive, but players can be relatively unconcerned about their own player-character, since when the player-character in a video game dies, they often immediately return with no adverse effects at all. This dynamic of player-characters easily coming back to life happens in The Walking Dead, but with the significant caveat that nonplayer characters can be hurt (emotionally and physically) or can die and leave the game for good-and consequences like these create high stakes for players who are emotionally attached to NPCs. These stakes are further raised in The Walking Dead with the addition of a timer, indicated by a bar that quickly shrinks (see the white bar above the player choices in Figure 2). If the timer expires before the player makes a choice, then the silent or passive choice is triggered, usually bringing with it the least desirable consequences.

Dialog choices in The Walking Dead, such as those pictured in Figure 2, lead to separate narrative branches that offer differences in the kind of "person" a player can choose to act in the game: violent toward others, for example, or kindly; again, these traits that players choose have meaning and emotional impact only in the context of character relationships, which are central to both story and gameplay in The Walking Dead. In one of the game's scenes, for example, the player-character (Lee) is asked by another character (Kenny) how the two of them should deal with an aggressive man who is threatening Kenny's son, a little boy named Duck. The choices available to the player (for Lee to act out) are pictured in Figure 3 and represent a range of approaches tied to very different character traits: from the kind and peaceful "Reason with him" option, to the violent "Kick his ass" choice.

3 Although The Walking Dead — as well as The Last of Us (Naughty Dog 2013), which is discussed later-both differ from Alien: Isolation in certain respects, the comparison is useful because of their similarities (all three games cross into the horror genre, and all include important narrative components). 


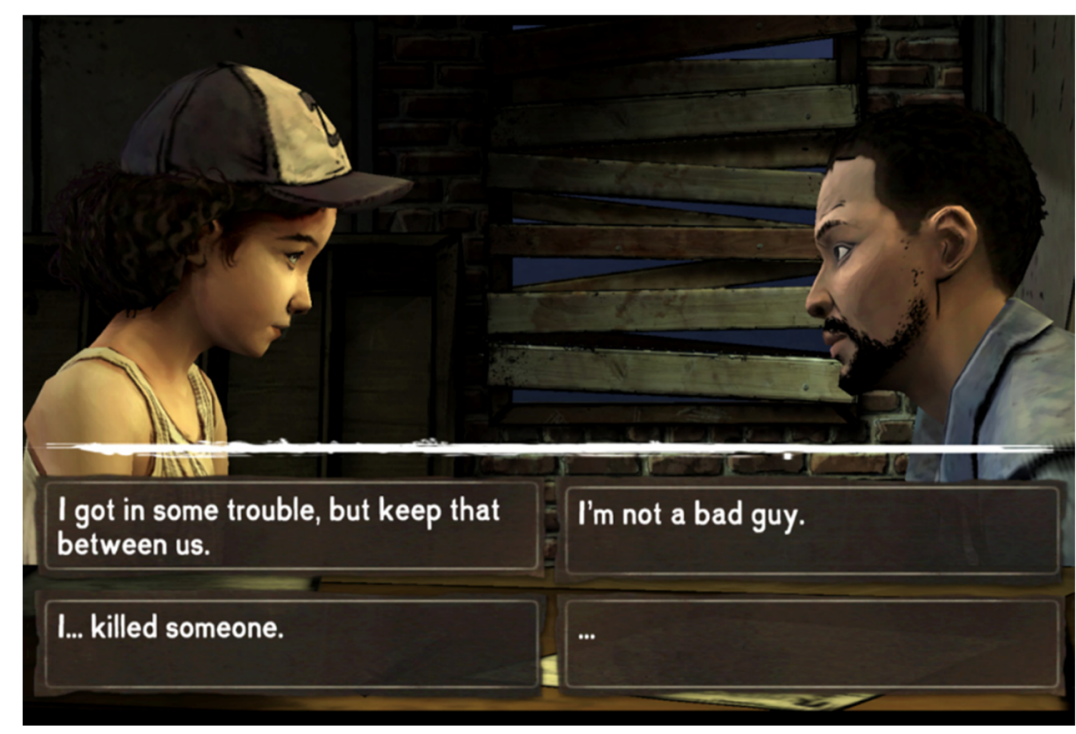

Figure 2. Dialog choices for the player-character, Lee (right), in conversation with Clementine (left), including the silent option (indicated by the ellipsis in lower right) and white timer bar in Telltale Games' The Walking Dead.

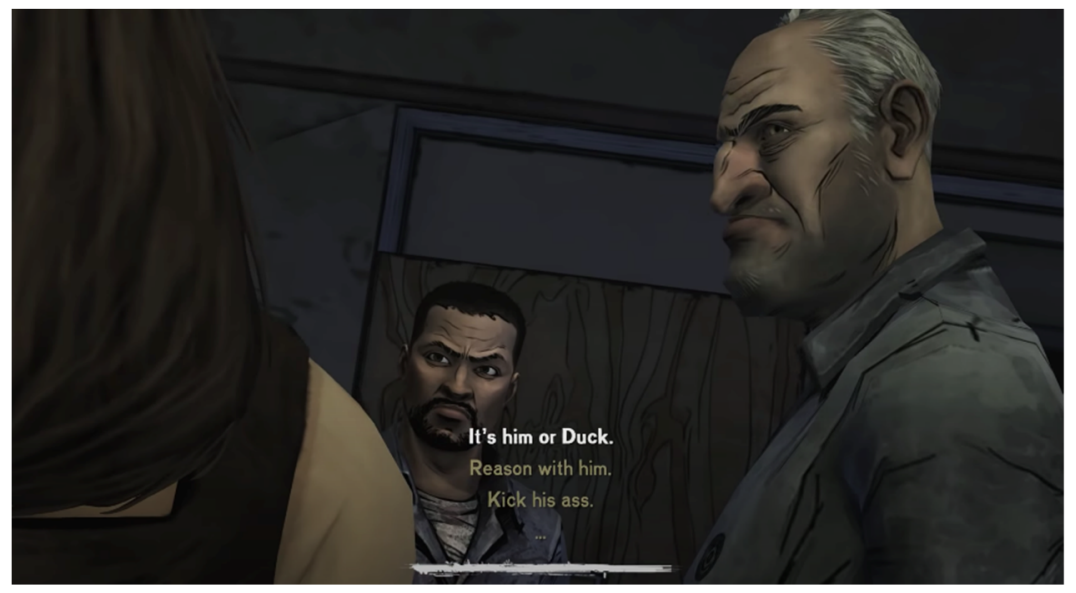

Figure 3. Options for the player-character, Lee (center) for dealing with an aggressive man (right) who is threatening Kenny's son, Duck.

The emotional stakes of the choice in Figure 3 are dependent on the player's feelings about the characters, which the writers of The Walking Dead exert significant control over. The writers know that many of us, as players, will naturally want to protect children; and they know that many of us will also naturally want to help our friends if aggressively attacked. The writers of The Walking Dead tap into both of these prosocial impulses by having Kenny-who previously befriended the player-character, Lee-beg us for help in dealing with the aggressive man attacking Kenny's young son, Duck.

How we help, though, is up to us. Again, our options are to intervene (with varying degrees of intensity), to do nothing (represented by the ellipsis), or to reason with the man threatening Duck. The option that is most faithful to the character the writers have established for Lee is probably the "Kick his ass" choice, since we learned early in the game that Lee is a convicted murderer. (In the first scene of the game, Lee is in the back of a police car heading to prison for the crime of murdering a man who was having an affair with his wife. The zombie apocalypse intervenes, the police car crashes, and Lee is freed.)

There is a potential problem involved with players who may not choose to role-play as Lee in a way that is faithful to the character that the writers have established. Many players may want to be "nice" on general principle, or because they think acting kindly 
will help them to succeed in the game. In the choice shown in Figure 3, this would mean choosing to "Reason with him" instead of taking a more extreme, even violent approach to protecting Kenny's son, Duck. Making the "nice" choice could mean undermining Lee's established character, and destroying a meaningful character arc for Lee, which could supply a good deal of satisfaction to players as they experience that arc being completed. Simply put, the issue here is that the moment the writers of The Walking Dead ceded control of the development of Lee's character to players, they stripped themselves of the ability to develop Lee in a way that might have included an emotionally moving character arc. For example, Lee might have begun the game as a hurt, angry, and violent man, but then learned to heal and control his rage through a slow process spanning the five episodes that comprise the game. But such a character arc would require Lee to act angrily and perhaps violently throughout much of the early part of the game.

This is actually the approach taken by writer Neil Druckmann in Naughty Dog's The Last of Us (2013), which won several BAFTA Games awards in 2014, including for Story and for Best Game. In the opening sequence of The Last of $U s$, the main player-character, Joel, loses his young daughter in the outbreak of the zombie apocalypse. The game then fast-forwards twenty years, and we, as players, see that Joel has become a deeply bitter and angry man. But Joel slowly learns to overcome his grief throughout the rest of the game, as he is forced to journey across the country with a teenage girl named Ellie. For most of the game, Joel is gruff, and sometimes outright cruel to Ellie. Many players, given an option (as in The Walking Dead), would never choose to treat a girl who is depending on them coldly or cruelly, except perhaps the few who are staunchly committed to role-playing as Joel in the way the writer establishes him-as grieving and angry.

But being forced to play a bitter and angry character for much of the game has a significant upside: by the end of the game, Joel completes an extremely satisfying character arc as his emotional wounds heal and he becomes a caring and protective father figure to Ellie. The actions of the new Joel-who treats Ellie as his own beloved daughter by the end of the game-take place in scenes and dialog that the player has no control over, just as in the beginning of the game when Joel is angry and bitter. It is the writer, Druckmann, who retains the power to develop Joel's character throughout the game, and he uses it to deliver what many consider to be an extremely fulfilling character arc and overall narrative experience. Player agency in The Last of Us does not reside in the realm of character development, but chiefly in the ability to move Joel (and Ellie, at times) throughout different environments, to collect raw materials and craft items, and to dispatch undead and living enemies.

The kind of agency that the writers of The Walking Dead cede to players makes it difficult for them to give Lee a sharp character arc like Joel has in The Last of Us. But The Walking Dead writers do manage to give a well-defined character arc to eight-year-old Clementine, who we, as Lee, protect and teach throughout the five episodes of The Walking Dead. By the end of the game, her arc is completed, and in a minor way, ours is too, as Lee: Clementine, with our guidance, has learned crucial skills (such as how to kill the undead walkers), and we know that she will be able to take care of herself in the post-apocalyptic world. We, as Lee, have prepared her, and so have completed our main goal of helping her. This, by the way, is a very different goal than the one we as players are given in Alien: Isolation, which is merely to survive, alone. Protecting other characters-helping them to survive-is a far more compelling goal, provided, of course, we care about those other characters. In The Walking Dead, the writers coax us into caring very much about Clementine, and we are able to redeem Lee for the murder he committed through the act of protecting, teaching, and parenting Clementine. In the process, however, we have been bitten by a walker and are close to "turning" at the end of the game. The last meaningful choice in The Walking Dead is whether to tell Clem to shoot us, so we will not turn into a zombie, or tell her to run away, sparing her that traumatic experience.

And here is where we also see the terrible choice the writers themselves faced when working on that scene: of the two options in The Walking Dead's ending sequence, watching 
Clem struggle to find the courage to not just take the easy out and escape, but to bravely raise the gun and kill us-her father-figure, Lee-in an act of mercy, is by far the most intense and satisfying (in a deeply emotional, tragic sense) for the player to experience. But the writers committed to giving players significant control over the ending. This means, on one hand, that some players experience a significantly less satisfying finale. On the other hand, all players are partially responsible for the ending they experience, which likely increases the overall level of emotional engagement in the game. In either case, the emotional involvement players feel in the ending of The Walking Dead ultimately depends on how much they come to care about the character they have the closest relationship to in the game-Clem.

The writers of Alien: Isolation begin with an attempt at developing characters that players care about: the game begins, after all, with a fairly promising (though truncated) cutscene which sets up a potential character arc for Amanda as a woman who will gain closure, or healing from the grief caused by the loss of her mother. The writers could have then taken another step in that direction by offering a new mother figure in the self-assured Captain Diane Verlaine (see Figure 4), whose ship takes Amanda and Samuels to Sevastopol Station.

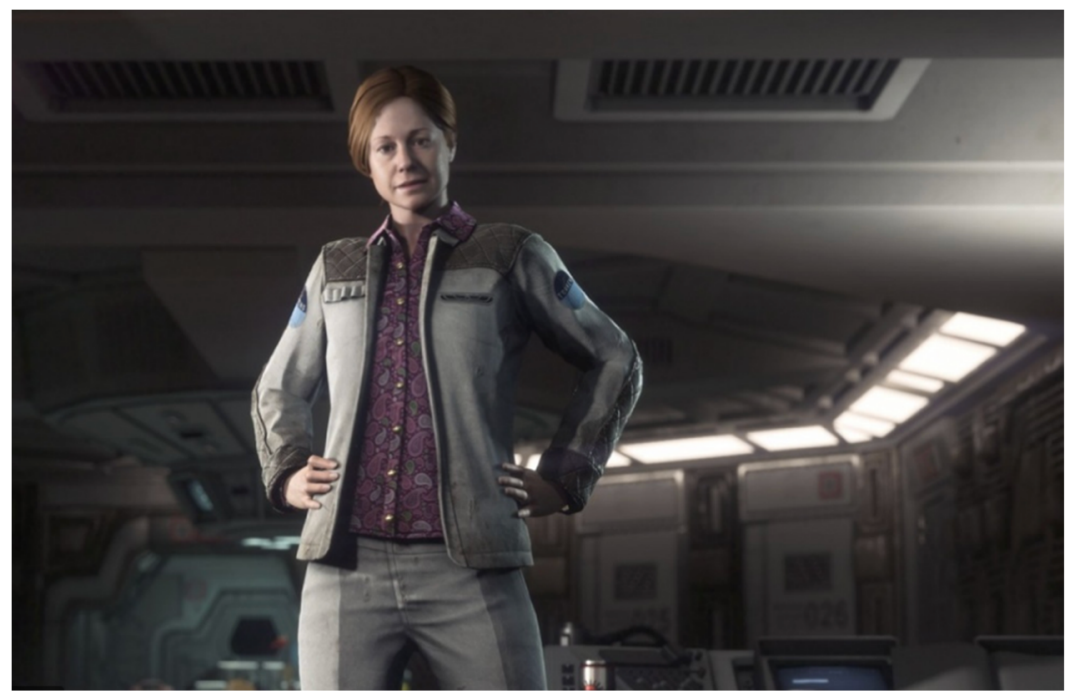

Figure 4. Potential mother figure, Captain Diane Verlaine, of the transport vessel Torrens.

Although that relationship with Verlaine never materializes, there is potential for players to create a meaningful bond with another character, Taylor, who accompanies Amanda and Samuels on the voyage. Just after the introductory cutscene fades to black, leaving us with the sound of a pumping heartbeat and the yearning to meet Ellen Ripley, we awake inside a hypersleep chamber. As we open our eyes and lift ourselves out of the chamber, we see the world from the perspective of Amanda. This awakening acts as a smooth transition from the cutscene-where we watch Amanda from a third-person perspective - to the first-person perspective we will inhabit for most of the game. The first-person perspective may add to immersion in a sense but deprives the player of seeing the facial expressions of the player-character for the rest of the game (barring the occasional cutscene), which reduces the player's sense of emotional attachment to the player-character.

After we wake up as Amanda, we dress ourselves and walk to the kitchen area of the transport ship Torrens, which is the same type of ship as the Nostromo from the film Alien. Sitting at a replica of the table where, in the film, the Alien bursts from Kane's chest, is Nina Taylor, who is the most developed NPC in Alien: Isolation. The majority of this development occurs in a short conversation we have with Taylor right there in the kitchen area, where she begins by complaining about hypersleep, saying, "I feel like death" - a phrase that echoes Kane's line, "I feel dead" from the beginning of the film Alien, and which in both 
cases foreshadows future events. Taylor goes on to tell us that the Nostromo's destruction "cost the Company a lot of money" and that if she, as a lawyer for the Company, can "close the case with a conclusive accident report, it'll look great with [her] superiors." Taylor is a very difficult character to bond with: She is a lawyer, which is a career that many people are suspicious of, and she is only out for herself: the reason she is there is to get ahead by pleasing the powerful executives who run the Company, which we know to be heartless and cruel. Once Taylor tells us about herself and her reason for being on the ship, to her credit, she apologizes for being "insensitive"; Amanda responds by immediately letting her off the hook, saying in an upbeat tone, "It's okay. We'll both get what we want, right?" This is frustrating: Amanda's response minimizes her very understandable grief and gives the Company-which, in effect, coldly murdered her mother-a pass. Nothing about the situation is "okay", despite what Amanda says, and for the writers to pretend so in an attempt to create a bond between these two characters undermines the emotional stakes of the game.

Next, the game's writers ask us to protect Taylor-an approach which works beautifully in The Walking Dead and The Last of Us. But unlike Clementine and Ellie, Taylor is not an innocent child who automatically inspires others to want to protect her, nor is she an adult we feel respect or sympathy for. If the writers had made Taylor a doctor, perhaps, or a teacher-someone who is dedicated to helping others-that Taylor might have inspired us as players to want to help and protect her in return.

Creating characters who strive to aid others is a key principle of character development described by Blake Snyder in the influential screenwriting manual, Save the Cat! "I call it the 'Save the Cat' scene", Snyder writes. "And it's basic. It's the scene where we meet the hero and the hero does something-like saving a cat-that defines who he is and makes us, the audience, like him" (xv). Although Snyder refers only to the hero here, the same principle can be applied to any character that the writer wants the audience, or player, to bond with. An obvious and literal example of this principle is Ellen Ripley's persistent attempt to save Jones the cat near the end of the film Alien, and she puts herself at great risk to do so. Happily, she succeeds in rescuing Jones, and the last line of dialog in the film has Ripley saying, "Come on cat" as she smiles warmly down at Jones (Figure 5), petting him and then putting him into a hypersleep chamber with her. Ripley's character is largely defined by how much she cares for the other characters throughout the film-not just Jones, but her shipmates as well.

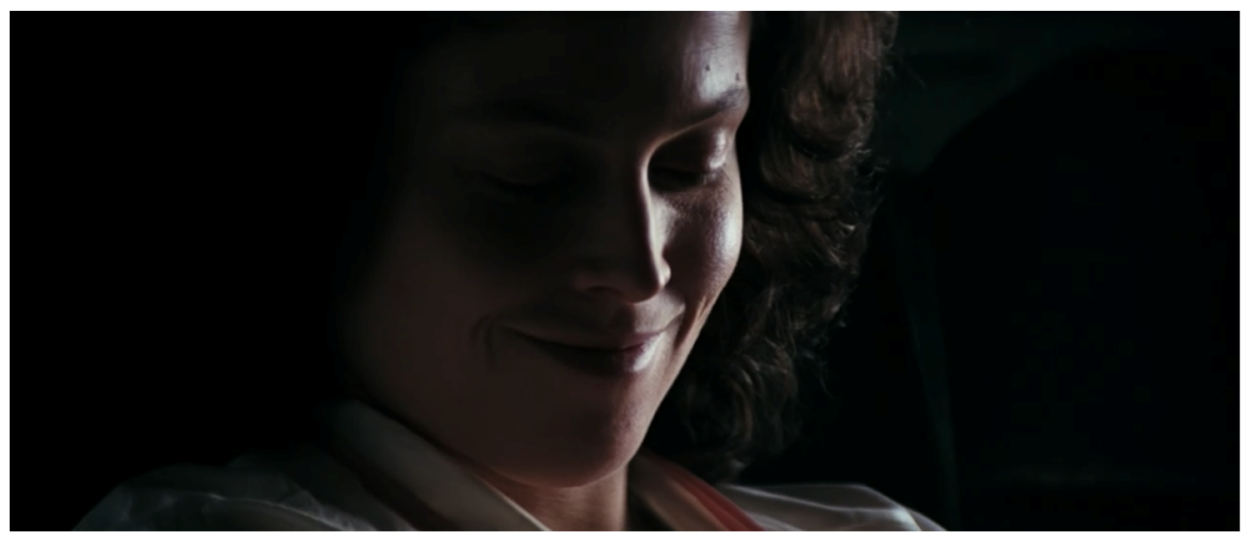

Figure 5. Ellen Ripley petting Jones at the end of Alien: "Come on, cat."

Ripley's actions in both Alien and Aliens are motivated primarily by saving the characters she cares about, not by the desire to kill. There is a common perception, though, that killing is the primary goal. Dawn Stobbart, for example, in Video Games and Horror: From Amnesia to Zombies, Run! writes that "As in the film, the player knows that the central premise of Alien: Isolation is to kill the Xenomorph-after all, this is an Alien game" (Stobbart 2019, p. 79). This perspective-that killing is or should be the focus, as opposed 
to saving (particularly in video games)—is echoed by Bryant and Giglio in Slay the Dragon: Writing Great Video Games:

In the groundbreaking book on Hollywood screenwriting, Save the Cat! the late Blake Snyder showed us how important it is for us in the movie audience to invest emotionally in the hero. He called those scenes "Save the Cat scenes". Video games have a very similar but more active principle: The players have to invest emotionally in the journey you've laid out for them. The player wants to slay the dragon. (Bryant and Giglio 2015, p. 26)

Bryant and Giglio do not say here exactly how slaying the dragon will allow the player to invest emotionally in the journey, although they imply that the "active principle" involved in slaying will somehow accomplish it. Their emphasis is on killing, but saving is also an act. The "Save the Cat" principle applies to situations beyond simply scenes in the beginning of stories that help audiences to root for the main character: saving another can be the overarching goal that a player-character pursues in game, and an action they take in the climax. Of course, killing is the central goal in many video games and films, but killing in order to save another character has an added emotional and motivational layer beyond simple bloodlust or the desire for revenge. Saving is Ripley's focus in Alien and Aliens, and that focus gives meaning and emotional weight to the destructive acts she undertakes.

According to J.W. Rinzler, author of The Making of Aliens (2020), Sigourney Weaver (who plays Ellen Ripley) expressed extreme discomfort to director James Cameron before filming scenes where Ripley kills several Aliens: "What they [Weaver and Cameron] bonded on", Rinzler says, "was she was doing it [killing Aliens] now to save this little girl [Newt]. And as most fans of the franchise know, originally there was a scene with her learning about her daughter's death, which was cut but then reinstated in the longer version. So it became about something else, so she had a higher reason for doing the massacres" (Collura 2020). Weaver and Cameron's focus on character relationships is clear in Aliens, and it adds meaning and emotional stakes to the many action sequences and "scares" in the film.

Although in Aliens, the audience knows from the start that Ripley is the main character through whom they will experience the story, in the beginning of Alien, no character stands out as the hero or heroine-it is very much an ensemble piece. The first stage of the Hero's Journey, the Ordinary World, shows us a ragtag crew who repeatedly joke with each other (contrary to this, there is no humor to be found in Alien: Isolation) but who are also divided sharply along class lines, with Parker and his technician Brett complaining because they are each receiving less compensation than the others. This and other conflicts among the crew help to build a fictional world the audience can believe in because it is grounded in realistic details that reflect inequalities in our own world. Including a large dose of realism is an approach that is crucial to the success of horror stories with "fantastic" elements, as Morrell (2017) points out in the introduction to the fiftieth anniversary edition of Ira Levin's iconic 1967 horror novel, Rosemary's Baby:

Levin's tactical decisions began with the necessary date on which Rosemary's baby would be born-25 June, the opposite of 25 December and the celebration of Christ's birth. The period in which the novel occurs is 1965-1966. Determined to provide numerous details to support his outlandish plot, Levin counted nine months back from 25 June 1966, and collected newspapers that provided accounts of the major events in Manhattan at that time: an electrical blackout, John Lindsay's mayoral campaign, a strike at The New York Times, and most important, Pope Paul VI's visit to New York City and the Yankee Stadium mass at which the Pope officiated (approximately when Rosemary-note the second part of her name-is impregnated). All of these documentary details and others, such as the best places to buy cheese and swordfish steaks in Manhattan, Levin incorporated into the novel to make what he called his "unbelievabilities" believable ... 
The novel's initial tone reads like a case history, comparable to the historical details that support the plot. "Rosemary and Guy Woodhouse had signed a lease on a five-room apartment in a geometric white house on First Avenue when they received word, from a woman named Mrs. Cortez, that a four-room apartment in the Bramford had become available".

Hardly the way we expect a horror novel to begin. (viii-ix; emphasis added)

The same can be said of Alien, which begins slowly, grounding us in the mundane details of life aboard an old tugboat of a ship that is hauling a distinctly unglamorous cargo of mineral ore. The first "action" scene only comes halfway through the film, a full fifty-five minutes in, when the Alien bursts out of Kane's chest. Before that, we get to know each of the crew members living in the Ordinary World quite well, as they confront the Call to Adventure in the form of an acoustical beacon coming from a nearby planetoid. Parker then voices the Refusal of the Call by saying that it is not in his "contract to do this kind of duty", which also further develops his rebellious personality. Ash, whose character is later revealed to be the personification of the inhuman Company, responds that the beacon must be investigated, under "penalty of total forfeiture of shares". This act foreshadows Ash's real agenda, which is to find and protect the Alien, and with Captain Dallas's support (Dallas's creed is to "do what the hell they tell you to do"), the Call to Adventure is affirmatively answered.

A fairly long (almost five-minute) sequence follows in which the crew pilot the Nostromo down to the surface of the planetoid. The sequence includes several realisticsounding lines like, "Roll 92 degrees port yaw" and "Give me an E.C. pressure reading" as the Nostromo flies through heavy turbulence, its old hull groaning under the strain before suffering damage in a botched landing on the planetoid. This damage is described by Parker as relating to three of the four cells of the "secondary load-sharing unit", which are gone, requiring "dry dock". Details of this kind, which are granular, give us a strong sense of the difficult and complex "realities" that the crew face in landing on the unfamiliar and unforgiving planetoid, LV-426. The characters' intense struggle here satisfies Vogler's Meeting with the Mentor stage, in which the hero (represented by the crew as an ensemble, in this case) must reach "within to a source of courage and wisdom" to continue the journey (Vogler and McKenna 2011, p. 33). The realistic details and struggles also serve to ground the story at the pivotal moment preceding the potentially impossible-to-believe discovery of a derelict spaceship with Alien eggs in its cargo hold.

Three members of the crew-Dallas, Kane, and Lambert-walk out to explore the derelict ship, which is the source of the acoustical beacon. Meanwhile, back on the Nostromo, Ellen Ripley analyzes the transmission, telling Ash it does not appear to be an SOS, but that "it looks like a warning". She concludes by saying she is going to go after her shipmates; Ash, however, convinces her to stay, saying that by the time she gets there, they will know whether or not it is a warning. Even though Ripley does not act on her instinct here, which is very much based on the "Save the Cat" principle, we have the sense that she truly wants to go and help her fellow crew members. When the explorers finally return, one of them, Kane, has an organism attached to his face. Captain Dallas orders Ripley to open the hatch and let them on board the ship, but Ripley refuses, saying that if she lets them in before they are decontaminated (per quarantine protocol), the crew "could all die".

Crucially, though, we see Ripley hesitate before she makes the decision to deny her shipmates entry, and when she finally does decide, she says, "No", softly, with a tangible sense of regret. We know that this is not easy for her. Ripley is not tough to the point of being cold and uncaring; she is sensitive and vulnerable, but with the strength to do the right thing even though it is difficult. We see this same quality of sensitivity mixed with strength when Ripley later volunteers to go into the air shaft to confront the Alien. But, after Dallas refuses this offer and decides to go himself, we see her deep caring for Dallas through the long, concerned look she gives him.

In the air shaft, Dallas loses his composure and tries to flee, and it is only then that the Alien comes for him, as if his fear has awakened the Alien's predatory instinct. Lambert 
later dies because she freezes in fear, Parker because he rashly gets too close to the Alien (Kane dies for the same reason); Brett dies because he fails to heed the warning of the Alien's shed skin; Ash dies because he prioritizes-just as the Company does-the Alien over the lives of the crew members. In this way, the film metes out justice to characters who are careless, unprincipled, or impulsive, while finally rewarding Ripley with the triumphant sight of the Alien being blasted away by the engines of her escape shuttle, and then with the soft embrace of Jones, her purring companion.

In Save the Cat!, Blake Snyder writes that "in many ways, a good screenplay is an argument posed by the screenwriter, the pros and cons of living a particular kind of life, or pursuing a particular goal" (Snyder 2005, p. 73). Similarly, Carly Kocurek makes the point in "Walter Benjamin on the Video Screen: Storytelling and Game Narratives" that effective stories-including video game narratives-offer "'counsel', or meaningful wisdom or advice" to their audience (Kocurek 2018, p. 9). The film Alien makes the argument, or gives the counsel, that, like Ripley, we must feel our emotions deeply in order to remain human and closely connected to others, but that we must not let them rule us. If we control our emotions, such as grief and fear, without going to the extreme of becoming cold, disconnected, and robotic (like Ash), then we can courageously confront our greatest fears and triumph over them.

In its best moments, Alien: Isolation makes this same argument through gameplay. The core of Alien: Isolation is, as Alistair Hope of Creative Assembly envisioned, a "one-on-one struggle" with the Alien. It essentially seeks to mimic, in a twenty-plus hour game, the last twenty minutes of the film Alien, where Ripley is alone with the monster (with the notable exception of Jones, of course). The gameplay in Alien: Isolation has us, as Amanda, sneaking through Sevastopol Station, desperately trying to avoid the Alien while seeking a way to escape. One of the most compelling aspects of the gameplay is that it enhances our fear, in part, by denying us the option of killing the Alien for most of the game. The best we can do is hide, or creep slowly forward. We often hear the Alien moving in the air vents above us, or stalking nearby, and in those moments, there can be an intense desire to run. But if we do, the Alien will sense our panicked movement and we will die like Dallas does, because we rashly fled. The gameplay teaches us, through several deaths, that, like Ripley, we must control our fear in order to triumph over the Alien.

The larger goals associated with this aspect of gameplay, however, do not resonate emotionally beyond periodic moments of terror because they do not relate to characters that we, as players, have bonded with. Again, "Save the Cat" need not just refer to a quality of helpfulness that makes a character likable; helping, or saving a beloved character, can also make for a compelling goal, both in movies and games. This is the guiding principle for many of Ellen Ripley's actions in Alien. James Cameron, in the sequel, also takes great advantage of this approach by giving Ripley the goal of healing through regaining a family; she gains this new family by bonding with and protecting Newt, her new daughter figure, as well as the romantic/spousal figure of Hicks, and an uncle figure of sorts in the android Bishop.

In Alien: Isolation, the only player goals that are centered on another character who is physically present in the game involve Taylor. In one mission, we are tasked with saving Taylor by finding a medical kit for her. And in a later mission, we unsuccessfully try to stop an overloading reactor from exploding near her. But neither goal is emotionally driven because we have not bonded with Taylor. As for the early goal of trying to find "closure" in the contents of the Nostromo's flight recorder, this is accomplished about halfway through the game. The recorder contains a message from Ellen to Amanda, in which Ellen explains that she had kill the Alien (by destroying the Nostromo) in order to protect Amanda and the rest of humanity. This is something of a letdown, since the recorder's message does not include any real surprises or emotional impact. Even if it had, once the goal of finding the recorder is reached, a replacement goal is now needed for the second half of the game. The goal of escaping alone is comparatively thin, as the importance of Jones in the end of Alien and Newt in finale of Aliens demonstrates. Again, Captain Verlaine of the Torrens could 
have become Amanda's new mother figure; after all, Verlaine is the captain of just the kind of ship that Ellen Ripley might well have eventually commanded had the events of Alien not intervened. We, as Amanda, might have bonded with Verlaine through cooperating to finally kill the monster together.

The game's last Alien, however, is defeated in a scene involving no cooperation with other characters, and with only minimal interactivity. We, as Amanda, have managed to escape the space station and get aboard the Torrens again, and the Alien comes after us in a quick time event: after we hit a button which opens the airlock, the scene fades to black. The next thing we see is Amanda in space (in a cutscene)—apparently, she was ejected from the ship along with the Alien, which is nowhere to be seen. The game ends with Amanda floating off into empty space (Figure 6) —expressionless, emotionless, and alone.

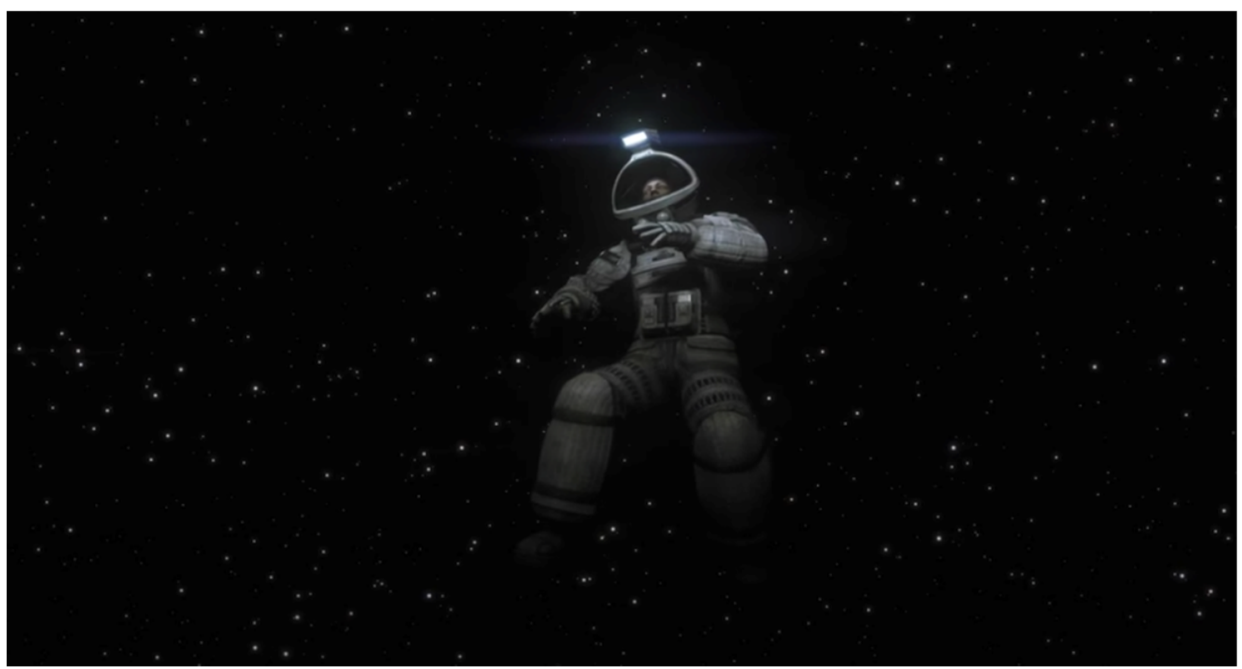

Figure 6. Amanda Ripley receding into empty space at the end of Alien: Isolation.

Compelling stories and characters have difficulty thriving in a vacuum. If the developers of Alien: Isolation had followed the blueprint provided by the film they were looking to for inspiration (Alien), they would have created more than just a realistic and sometimes terrifying game of "cat-and-mouse". Instead, they would have developed rich characters, partly through respecting the distinct stages of the Hero's Journey, and partly by fully capitalizing on the character relationships used to so successfully in Alien, Aliens, The Walking Dead, and The Last of Us. They would have created at least one character for the player to bond deeply with, protect, and perhaps even save. Then Amanda Ripley, and the people playing as her, might end the game feeling that sense of "closure" and emotional fulfillment they were seeking all along.

Funding: This research received no external funding.

Conflicts of Interest: The author declares no conflict of interest.

\section{References}

Bates, Bob. 2005. Into the Woods: A Practical Guide to the Hero's Journey. Gamasutra, June 17. Available online: https://www. gamasutra.com/view/feature/130742/into_the_woods_a_practical_guide_.php (accessed on 12 July 2020).

Bryant, Robert, and Keith Giglio. 2015. Slay the Dragon: Writing Great Video Games. Studio City: Michael Wiese Productions.

Cameron, James, dir. 1991. Aliens: Special Edition. Hollywood: 20th Century Fox.

Campbell, Joseph. 1949. The Hero with a Thousand Faces. New York: Pantheon Books.

Collura, Scott. 2020. The Making of Aliens: Mutiny, Lawsuits, and James Cramer-Who? IGN, August 31. Available online: https:/ / www.ign.com/articles/the-making-of-aliens-titan-rinzler-james-cameron-gale-anne-hurd (accessed on 12 June 2020).

Costuic, Stanislav. 2016. The Hero's Journey of Journey. Gamasutra, October 13. Available online: https://www.gamasutra.com/blogs / StanislavCostiuc/20161013/283288/The_Heros_Journey_of_Journey.php (accessed on 6 August 2020).

Creative Assembly. 2014. Alien: Isolation. Tokyo: Sega. 
Delmas, Guylain, Ronan Champagnat, and Michel Augeraud. 2007. Bringing Interactivity into Campbell's Hero's Journey. In Virtual Storytelling: Using Virtual Reality Technologies for Storytelling. Berlin: Springer.

Dunniway, Troy. 2000. Using the Hero's Journey in Games. Gamasutra, November 27. Available online: https://www.gamasutra.com/ view / feature/131527/using_the_heros_journey_in_games.php?page=3 (accessed on 3 July 2020).

Gearbox Software. 2013. Aliens Colonial Marines. Tokyo: Sega.

Iacobo, Maria. 1994. THE BIZ: A Memo's Journey. Los Angeles Times, November 13. Available online: https://www.latimes.com/ archives/la-xpm-1994-11-13-tm-61952-story.html (accessed on 1 July 2020).

Ip, Barry. 2011. Narrative Structures in Computer and Video Games: Part 1: Context, Definitions, and Initial Findings. Games and Culture 6: 103-34. [CrossRef]

Keogh, Brendan, and Darshana Jayemanne. 2018. "Game Over, Man. Game Over": Looking at the Alien in Film and Videogames. Arts 7: 43. [CrossRef]

Kocurek, Carly A. 2018. Walter Benjamin on the Video Screen: Storytelling and Game Narratives. Arts 7: 69. [CrossRef]

Lebowitz, Josiah, and Chris Klug. 2011. Interactive Storytelling for Video Games: A Player-Centered Approach to Creating Memorable Characters and Stories. Amsterdam: Elsevier.

Madigan, James. 2012. The Walking Dead, Mirror Neurons, and Empathy. Psychology Today, November 3. Available online: https:// www.psychologytoday.com/us/blog/mind-games/201211/the-walking-dead-mirror-neurons-and-empathy (accessed on 5 June 2020).

Morrell, David. 2017. Introduction. In Rosemary's Baby, 50th Anniversary ed. Edited by Ira Levin. New York: Pegasus Books, pp. v-xiii.

Naughty Dog. 2013. The Last of Us. Minato City: Sony Computer Entertainment.

Price, Ronan. 2014. Alien Isolation interview: We wanted it to be really scary. The Irish Independent, October 3. Available online: https: / /www.independent.ie/entertainment/games/previews/alien-isolation-interview-we-wanted-it-to-be-really-scary30635292.html (accessed on 1 July 2020).

Pugh, Tilson. 2018. The Queer Narrativity of the Hero's Journey in Nintendo's The Legend of Zelda Video Games. Journal of Narrative Theory 48: 225-51. [CrossRef]

Rinzler, Jonathan. W. 2007. The Making of Star Wars. New York: Del Rey.

Scott, Ridley, dir. 1979. Alien. Hollywood: 20th Century Fox.

Snyder, Blake. 2005. Save the Cat! The Last Book on Screenwriting You'll Ever Need. Studio City: Michael Wiese Productions.

Stobbart, Dawn. 2019. Video Games and Horror: From Amnesia to Zombies, Run! Cardiff: University of Wales Press.

Telltale Games. 2012. The Walking Dead. San Rafael: Telltale Games and Skybound Games.

Vogler, Christopher, and David McKenna. 2011. Memo from the Story Department: Secrets of Structure and Character. Studio City: Michael Wiese Productions.

Weise, Matthew, and Henry Jenkins. 2009. Short Controlled Bursts: Affect and Aliens. Cinema Journal 48: 111-16. [CrossRef] 